\title{
Bony contouring in head and neck microvascular reconstruction
}

\author{
Joshua J. Kain, Andrew C. Birkeland, Arnaud F. Bewley \\ Department of Otolaryngology-Head \& Neck Surgery, University of California Davis, UC Davis Health, Sacramento, CA 95817, \\ USA. \\ Correspondence to: Arnaud F. Bewley, Department of Otolaryngology- Head \& Neck Surgery, University of California Davis, UC \\ Davis Health, 2521 Stockton Boulevard, Suite 7200, Sacramento, CA 95817, USA. Email: abewley@ucdavis.edu
}

How to cite this article: Kain JJ, Birkeland AC, Bewley AF. Bony contouring in head and neck microvascular reconstruction. Plast Aesthet Res 2021;8:21. https://dx.doi.org/10.20517/2347-9264.2020.229

Received: 31 Dec 2020 First Decision: 5 Feb 2021 Revised: 11 Feb 2021 Accepted: 3 Mar 2021 Available online: 4 Apr 2021

Academic Editor: Matthew Spector Copy Editor: Xi-Jun Chen Production Editor: Xi-Jun Chen

\begin{abstract}
Head and neck reconstruction has evolved substantially in the last three decades to rely heavily on microvascular free tissue transfer, including bony composite flaps that improve form and functional outcomes. The technologies available for planning and executing bony reconstruction have undergone concurrent innovation, leaving the modern surgeons with a host of options to consider. In this review, the techniques of external fixation, virtual surgical planning and rapid prototyping are discussed with the aim of familiarizing surgeons and comparing these approaches. External fixation, though not new to head and neck surgery, has seen a revival and has considerable utility in vascularized bony reconstruction with the potential for improved efficiency and cost control. We explore the clinical situations in which virtual surgical planning is best employed, and the varying levels to which it can be applied throughout the reconstructive process. The ever-expanding realm of rapid prototyping, or 3D printing, is also examined to explore potential applications for surgical modeling, tissue engineering and even clinical training. Finally, we present a discussion of the cost-effectiveness of the technologies and future directions for research in the field.
\end{abstract}

Keywords: Head and neck, microvascular reconstruction, external fixation, virtual surgical planning, rapid prototyping

\section{INTRODUCTION}

The goals of head and neck reconstructive surgery include preserving both form and function after 
oncologic resections. The general reconstructive principle of replacing "like tissue with like tissue" demands the use of allograft, free or vascularized bone when segments of the maxilla, mandible or craniofacial skeleton are resected. Maintaining pre-operative occlusion and contour of the mandible can prove challenging when the act of tumor resection causes destabilization and discontinuity of the remaining bone. Multiple strategies have been developed to optimize outcomes in bony contouring of the maxillofacial skeleton. Herein, we visit three techniques to accomplish functional reconstructions when utilizing bony composite free tissue transfer: external fixation devices, virtual surgical planning, and rapid prototype modeling.

External fixation (EF) devices were described for the treatment of general orthopedic fractures as early as 1843 and for the treatment of mandibular fractures by $1946^{[1,2]}$. EF refers to the process of placing anchoring pins in fractured bony segments which are then aligned and stabilized by an external rigid frame $e^{[3]}$. In contemporary maxillofacial trauma, EF is employed in complex fractures when internal fixation (IF) cannot be feasibly achieved. IF has become the hallmark treatment of traumatic or iatrogenic facial fracture repair because of improved fracture immobilization, faster bony union, and decreased hardware infectious complications ${ }^{[3]}$. However, IF is not always achievable in specific traumatic or oncologic cases and EF remains a useful technique. In the field of head and neck oncology, EF devices have been used to provide bony fixation during removal of a bony segment of the mandible or maxilla involved with a malignant or benign tumor. This fixation allows for maintaining anatomic alignment and occlusion during reconstruction.

Virtual surgical planning (VSP) had been introduced for maxillofacial trauma and oncologic reconstruction by $1999^{[4]}$. This technology allows surgeons to plan complex facial reconstructions preoperatively, which has evolved to become a means for planning bony microvascular free flap osteotomies to optimize cosmesis and function. VSP also allows for patient-specific plating which is customized reconstruction implants that account for the anatomy, tumor boundaries, and dental occlusion of an individual. VSP has been shown to decrease operative time and free flap ischemic time ${ }^{[5]}$. However, VSP carries a tremendous associated cost and success is dependent on preoperative oncologic margin determination.

Rapid prototyping (RP), commonly referred to as " $3 \mathrm{D}$ printing", makes a unique contribution to bony contouring in the head and neck. Similar to VSP, this technique can facilitate pre-operative planning based on idealized anatomy to arrive at three dimensional printed models for use in the operating room. This technique can be organized to become an internal process within an institution with the benefit of reducing costs and preparation time $\mathrm{e}^{[-8]}$.

Emphasizing cost-effective and evidenced-based practices, we review the application of EF, VSP and RP in head and neck microvascular reconstructions.

\section{Head and neck bony microvascular reconstruction}

The simplest strategy for restoring bony contour involves "pre-bending" an IF reconstructive plate to the native maxillofacial skeleton prior to tumor resection. In these situations, once the bony segment intended for extirpation is exposed, an IF implant is templated against the native bone surface prior to osteotomies and resection. However, when tumors involve the plating surface of the bone or contour is already compromised by fractures or erosion, this disruption can preclude the practice. For example, exophytic tumors of the buccal surface of the mandible can disrupt accurate contouring of a reconstructive plate along the outer cortex of the bone and spoil this contouring option. This predicament has fostered innovative approaches to bony fixation. 
We present here three strategies that can be employed to restore bony contour when using composite free tissue transfer and provide suggested applications for each.

\section{External fixation}

First reported in 1981, Bergman et al. ${ }^{[9]}$ showcased a series of 20 patients with oral and oropharyngeal cancers treated with an intraoperatively applied external fixator system for 12-14 weeks post-operatively. Notably, these patients were left "swinging" without bony replacement of the resected segments. The use of the system in this setting was aimed at preventing soft tissue contracture and the resulting deviation of the native mandible toward the resected side. In their series, they proved the feasibility of these strategies for oncologic segmental mandibulectomies reporting improvements in trismus, oral care, and no delay in receiving adjuvant chemoradiotherapies.

The next evolution of the technique came in 2001 with a Kirschner wire based system ${ }^{[10]}$. Louis et al. ${ }^{[10]}$ utilized this EF system for providing intraoperative stabilization of the mandible to facilitate en-bloc mandibular tumor extirpation. This was followed by application of a titanium IF reconstruction plate to bridge the resected segment. No bony replacement is described in their technique, leaving the reconstruction plate covered by soft tissue alone.

By the early 2000's, composite microvascular free-tissue transfer was reported citing improved bony union, decreased infectious complications and resorption when compared to free or allograft bony reconstructons ${ }^{[1-13]}$. The adjunct of temporary intraoperative EF and composite free flap reconstruction was introduced in a series of six patients successfully treated in $2002^{[14]}$. Their technique involved placing an EF device prior to tumor extirpation under wide mandibular exposure, and then removing the external bracketing during the bony osteotomies. The removal of the external frame allowed for increased working space during the oncologic resection. Once the mandibular segment was removed, the external frame was reapplied to the bone posts to restore the bony conformation. The vascularized bone grafts were then inset with titanium mini-plates and thereafter the device was explanted entirely. All six patients had complete bony union with no evidence of cross-bite deformities or condylar head dislocation and satisfactory external projection and contour ${ }^{[14]}$.

Apart from oncologic defects, EF has utility in traumatic injuries of the maxillofacial skeleton, congenital deformities, edentulous patients, and pathologic fractures with osteoradionecrosis. In a mixed series of 10 patients treated with a modern titanium EF system, Cornelius et al ${ }^{[15]}$ provided further support of the technique. Their population included eight patients with sequelae from treatment of their head and neck cancers including pathologic fractures, orocutaneous fistulas and locoregional tumor recurrences. They utilized EF as a stabilizing measure for a range of 40-170 days prior to converting to either IF hardware alone or vascularized bone transfer. Their experience shows EF as a means of allowing interval soft tissue wound healing to occur prior to definitive management with tissue transfer and IF to avoid hardware complications or malunion.

EF has also been shown to be a useful tool when tumor resection involves or necessitates removal of the mandibular condyle with or without portions of the adjacent maxilla. In these situations, intraoperative stabilization can be accomplished by capitalizing on the bony stability of the uninvolved zygoma or remaining maxilla as an anchoring point for an EF post. We do not routinely remove the EF hardware during the tumor resection and osteotomies, but instead fashion the conformation of the external frame in a way that facilitates adequate working space for the ablation [Figures 1 and 2]. 


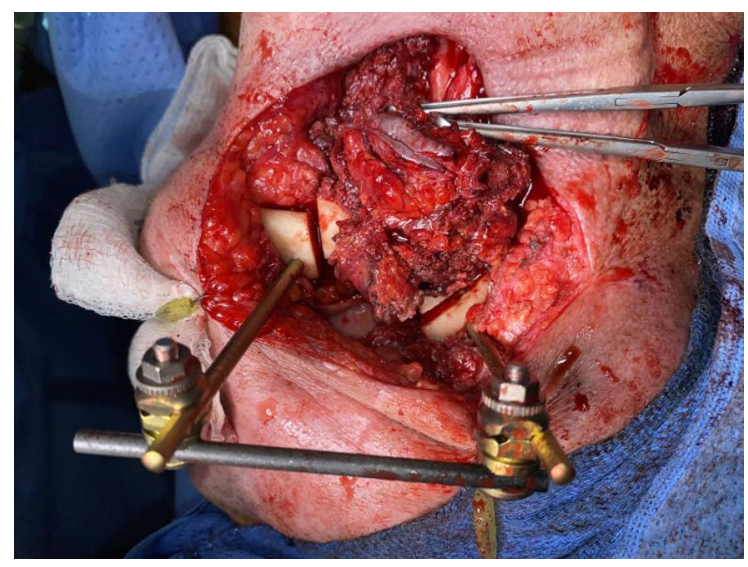

Figure 1. External fixation of a single segment mandibular reconstruction.

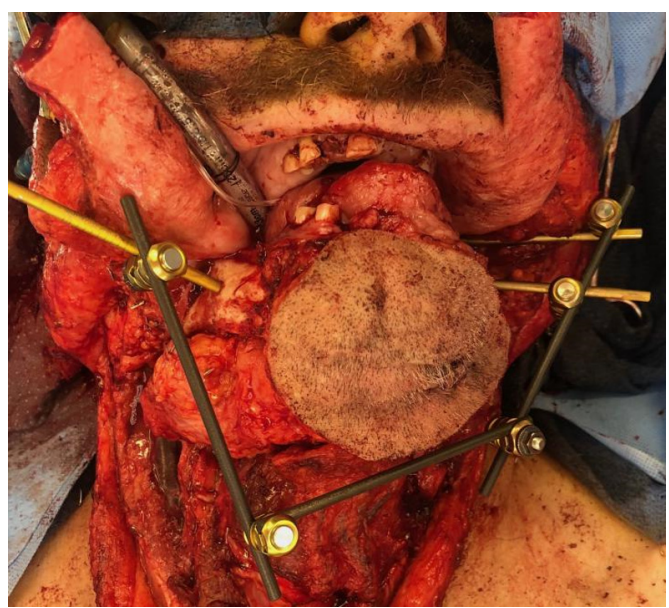

Figure 2. Anterior composite resection with external fixation intraoperative stabilization prior to scapula composite free flap reconstruction.

Though useful, EF is not without potential complications. When used in a temporary intraoperative manner, the primary concern is loosening of shifting of the apparatus disrupting the integrity of the alignment. In this situation, realignment through maxillomandibular fixation with traditional arch bars or interdental wiring is advocated in dentulous patients ${ }^{[3]}$. Pin placement through soft tissue can also result in facial nerve injury at a reported rate of $7 \%^{[3]}$. With intraoperative use only, the concern for pin-site infections or soft-tissue complications is minimal given the wide direct bony exposure typically required for tumor extirpation.

When considering the cost, the use of EF intraoperative can be compared to other modalities such as VSP. Since the construct is only used intraoperatively, the only implant charge is typically for the Schanz screws or posts that directly drill into the native bone at our institution. For example, in a case such as Figure 2 with an anterior composite resection construct, only the three Schanz screws pictured are considered implanted and charged for as the remainder of the construct is re-sterilized. This equates to approximately \$1200-2400 USD in hardware costs and can avoid the need for VSP and fabricated hardware costs. 


\section{Virtual surgical modeling and planning}

Imaging-guided surgical navigation, modeling and preoperative planning have been in development for craniofacial surgery since the 1990's, and with recent advances have gained widespread adoption in head and neck reconstruction ${ }^{[4,5,16-18]}$. The most common variant of this technology is often referred to as a VSP in which computed tomography studies are used to guide both resection margins and free flap osteotomies to recreate the bony defect using vascularized bone by free tissue transfer [Figure $3 \mathrm{~A}-\mathrm{C}$ ]. Culie et al. ${ }^{[5]}$ described their experience with VSP in 18 patients against a historic internal cohort showing decreased operative and ischemia time with use of the technology. This correlated with similar contemporary published series at the advent of VSP in mandibular reconstruction touting benefits of improved accuracy of the bony contour, improved aesthetics, and increased rates of bony union ${ }^{[19-22]}$. Supporting conclusions from these series cited the benefit of allowing for bony contouring in-situ at the donor site under perfused conditions prior to harvest of the osteocutaneous composite free flap. This lent to decreased ischemia time for the flaps while also allowing improved workflows when a two-team approach was utilized for ablative and reconstructive portions of the operations.

However, the cost-effectiveness of routine VSP use in head and neck reconstruction must be factored in a modern medical climate that prioritizes value. An institutional analysis by Fatima et al. ${ }^{[23]}$ estimated an average added cost of $\$ 7099$ per person with use of VSP over conventional strategies and described an increased rate of flap loss and post-operative infectious complications. Even with controls for decreased operative time and free-flap ischemia time, the added cost of VSP did not add objective value in their analysis ${ }^{[23]}$. Similar studies have supported VSP as an economically viable technology in head and neck reconstruction on the basis of saved operative time alone $e^{[24-26]}$.

There are situations in bony head and neck reconstruction that VSP offers a seemingly substantial advantage to other techniques. Guiding indications for the use of VSP have been suggested, which include: defects requiring multiple free flaps, defects involving multiple sites or subsites of the maxillofacial skeleton, the need for multiple osteotomies, presence of osteoradionecrosis or irradiated fields, or a history of a highvelocity ballistic injury with severe bony comminution ${ }^{[5,27]}$. In our review, no studies have focused specifically on the outcomes and cost-effectiveness of VSP in the setting of these specific indications compared to less complex reconstructions.

\section{Rapid prototyping for head and neck reconstruction}

Used as either an adjunct or substitute for VSP systems, RP or three-dimensional printing has proved valuable in the realm of head and neck reconstruction. RP refers to the process of generating a physical model from digital data taken from a computed tomography or magnetic resonance image, commonly referred to as " $3 \mathrm{D}$ printing". There are various methodologies for creating these medical prototypes which can be either inert or biologic depending on the anticipated application. The technique for rendering these models also varies both by equipment and process. Modeling can be either additive or subtractive in nature. In additive processes, a model is built de novo by sequential on-laying of the desired material to gradually create a final prototype. Conversely, subtractive processes utilize removal of material from an existing block to arrive at a final model ${ }^{[28]}$. Both processes are utilized in modern head and neck reconstructive applications depending on the usage of the material.

RP can be utilized at multiple levels of the head and neck reconstruction process. It can be utilized to build either patient-specific implants such as inert titanium plating for maxillary or mandibular reconstruction or for biologic implants such as tissue scaffolding ${ }^{[6-8]}$. RP can also be employed to build tailored cutting guides based on image-guided modeling to improve the osteotomy accuracy in bony contouring. Finally, RP can be used to create patient-specific idealized craniofacial models to allow for ex vivo reconstruction plate 

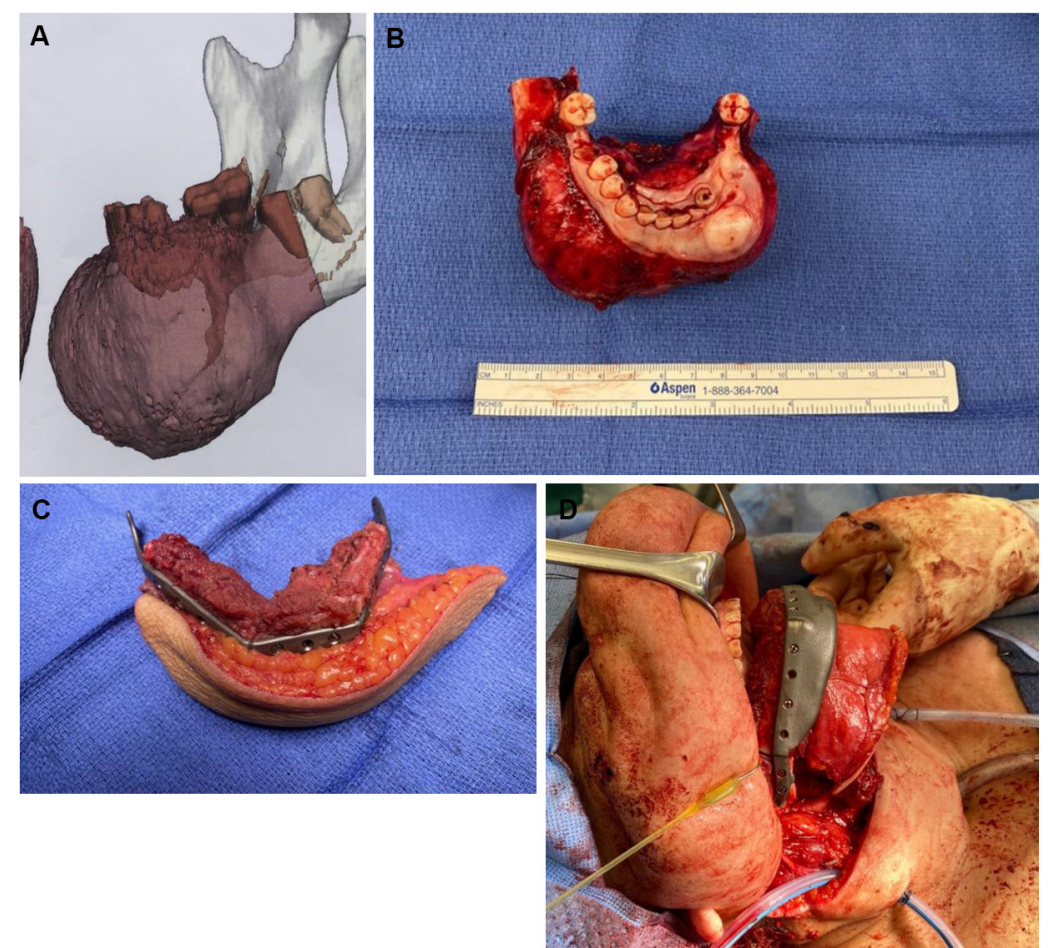

Figure 3. Anterior mandible ossifying fibroma with 3D reconstructed imaging for VSP (A). Ossifying fibroma specimen after anterior composite resection (B). Ex vivo bony contour of a fibula composite free flap reconstruction with VSP after closing osteotomies made with pre-fabricated cutting guides (C). Reconstruction with the three segment fibula composite flap in vivo with a patient specific implant reconstruction plate (D). VSP: Virtual surgical planning.

contouring and bony segment templating in the absence of VSP cutting guides ${ }^{[29-31]}$ [Figure $\left.4 \mathrm{~A}-\mathrm{C}\right]$. Mirror image digital processing can be incorporated to create idealized contours from the non-diseased side of the maxillofacial skeleton to avoid contour disruptions from an exophytic or destructive tumor.

An increasing number of institutions have moved to internal RP production to mitigate the cost and time required in formal $\mathrm{VSP}^{[32]}$. The $3 \mathrm{D}$ printer equipment costs have been estimated as minimal as $\$ 1000 \mathrm{USD}$ with material costs for printing these models reaching \$1 USD and 4-5 h of printing time required per application ${ }^{[32]}$. This has expanded the usage of RP in many medical centers and allowed for increasing research and educational applications in head and neck reconstruction. Table 1 gives a generalized comparison of the available modalities for bony contouring of head and neck defect reconstruction.

\section{DISCUSSION}

The modern head and neck microvascular surgeon has numerous tools at their disposal to improve functional and aesthetic outcomes. With these advancements comes a need for heightened discretion in resource utilization without compromising health care quality. Here we review several developments in head and neck bony reconstructive contouring in hopes of familiarizing surgeons with various available techniques. Thoughtful application of these tools on a tailored case by case basis can mitigate costs and optimize outcomes in head and neck reconstruction.

Though EF is an older technique with significant historical precedent, its role relative to more modern techniques such as VSP and RP should be evaluated. Perhaps the most distinct advantage of intraoperative $\mathrm{EF}$ temporary fixation lies in situations where defects cross the temporomandibular joint. Using EF in these 
Table 1. Comparison of bony contouring modalities

\begin{tabular}{|c|c|c|c|c|}
\hline Modality & Advantages & Drawbacks & $\begin{array}{l}\text { Associated cost } \\
\text { categories }\end{array}$ & $\begin{array}{l}\text { Preoperative } \\
\text { planning }\end{array}$ \\
\hline $\begin{array}{l}\text { Virtual surgical } \\
\text { planning }\end{array}$ & $\begin{array}{l}\text { - Patient specific } \\
\text { - Ideal bony contours } \\
\text { - Reduced operative time } \\
\text { - Improved bony unions } \\
\text { - Surgeon/Manufacturer coordinated } \\
\text { planning }\end{array}$ & $\begin{array}{l}\text { - Poor intraoperative } \\
\text { adaptability } \\
\text { - Required technical } \\
\text { familiarity } \\
\text { - Preoperative planning } \\
\text { consultation time }\end{array}$ & $\begin{array}{l}\text { - Additional imaging } \\
\text { - Modeling, fabrication, } \\
\text { delivery } \\
\text { - Patient specific implants } \\
\text { - Patient specific cutting } \\
\text { guides }\end{array}$ & $\begin{array}{l}\text { - Modeling } \\
\text { - Fabrication } \\
\text { - Delivery } \\
\text { - Sterilization } \\
\text { - Personnel } \\
\text { (representatives) }\end{array}$ \\
\hline Rapid prototyping & $\begin{array}{l}\text { - Patient specific } \\
\text { - Anatomic } \\
\text { - Reduced operative time }\end{array}$ & $\begin{array}{l}\text { - Required expertise } \\
\text { - Required equipment }\end{array}$ & $\begin{array}{l}\text { - 3D printer } \\
\text { - Materials } \\
\text { - Software } \\
\text { - Internal reconstruction } \\
\text { plate equipment }\end{array}$ & $\begin{array}{l}\text { - Modeling } \\
\text { - Printing } \\
\text { - Sterilization }\end{array}$ \\
\hline External fixation & $\begin{array}{l}\text { - Adaptability } \\
\text { - Anatomic } \\
\text { - Multi-segment or multi-component } \\
\text { reconstruction } \\
\text { - In vivo planning }\end{array}$ & $\begin{array}{l}\text { - Required technical } \\
\text { familiarity } \\
\text { - Placement and removal } \\
\text { time }\end{array}$ & $\begin{array}{l}\text { - External fixation equipment } \\
\text { - Internal reconstruction } \\
\text { plate equipment }\end{array}$ & - Equipment availability \\
\hline $\begin{array}{l}\text { In vivo plate } \\
\text { contouring }\end{array}$ & $\begin{array}{l}\text { - Time efficient } \\
\text { - Anatomic } \\
\text { - Familiar skill-set }\end{array}$ & $\begin{array}{l}\text { - Tumor location dependent } \\
\text { - Intraoperative time }\end{array}$ & $\begin{array}{l}\text { - Implantable equipment } \\
\text { only }\end{array}$ & - None \\
\hline
\end{tabular}
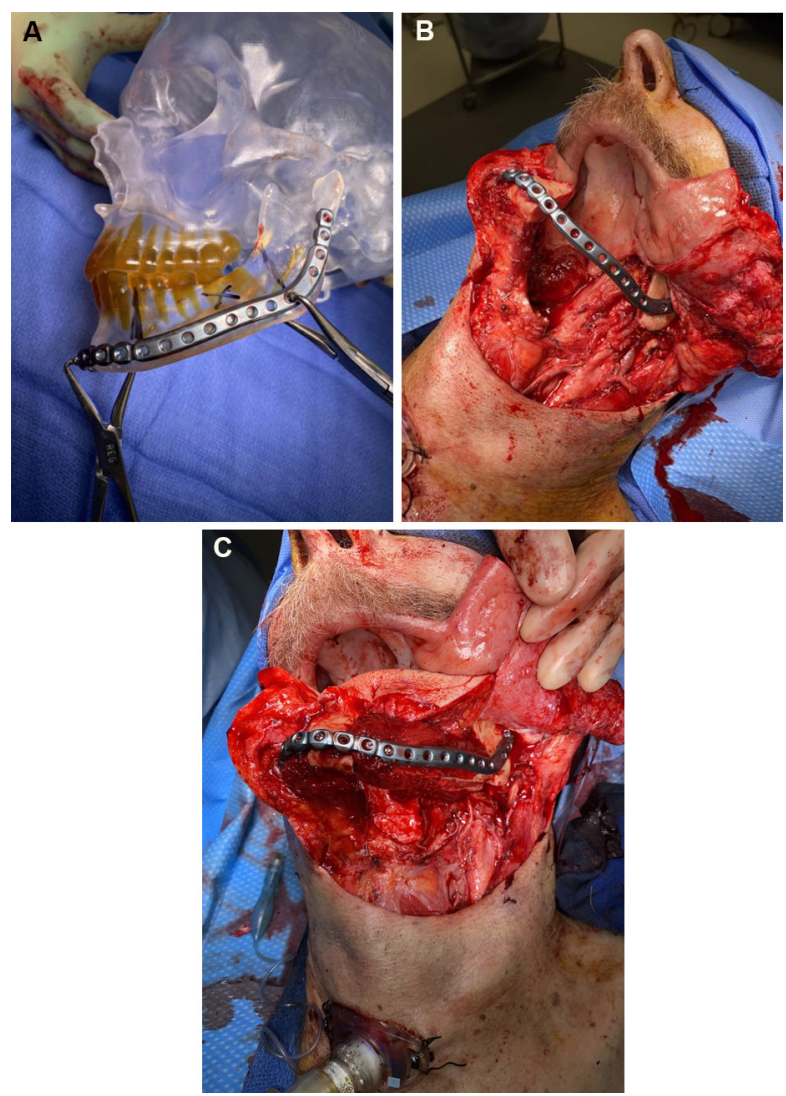

Figure 4. Templating utilizing a rapid-prototype model intraoperatively to achieve restored mandibular contour (A). Intraoperative photo showing the applied mandibular hardware after an oral composite resection of the left mandibular body (B). Reconstruction utilizing a subscapular system composite flap to achieve bony contour restoration (C). 
cases provides for time-efficient stabilization of the maxillomandibular relationship while preserving working space for complete tumor extirpation and subsequent vascularize bony reconstruction. We advocate for the use of EF or RP over VSP when the reconstruction requires only a single bony segment without multiple osteotomies and direct templating is not feasible due to tumor or defect constraints. An obvious limitation to the use of EF is a situation where there is not ample remaining bone stock for both proximal and distal application of the vertical posts for an external fixator apparatus. We readily recognize the distinct advantage of VSP in these scenarios and other multi-site or multi-segment reconstructions.

We advocate for the judicious use of VSP for the most complex reconstruction cases that are not amenable to a simpler approach. For example, VSP is optimal for multi-segment ( 3 or more) reconstructions and multi-site defects and should be routinely considered in these settings ${ }^{[5]}$. The routine use of VSP for irradiated patients or cases of osteoradionecrosis is not supported by our review of the literature barring the additional criteria of complex and multi-segmented reconstructions. The use of VSP for cases requiring multiple flaps should be evaluated based on the same considerations as cases requiring a single flap with emphasis on the bony contouring needs of the reconstruction.

A move towards in-house or onsite RP at various medical institutions has expanded its utility and holds enormous potential. Shared equipment can be utilized both intra-departmentally and across specialties to control up-front costs. RP can be used not only for clinical and research applications and various studies have shown the value of RP in clinical education ${ }^{[33-35]}$.

The additions of RP and EF to the armamentarium of the microvascular surgeon can offer a niche advantage while avoiding the costs of VSP in specific situations. For cases involving a single site (e.g., maxilla or mandible) tumor that is exophytic in nature, the use of RP modeling or intra-operative EF is often sufficient and avoids the need for patient-specific implant fabrication or VSP cutting guides. This also provides the added benefit of increased flexibility in oncologic margin control, allowing for an adaptable surgical plan. In our practice, RP and EF have anecdotally reduced operative times in a similar manner to the described benefits of VSP, though we have not quantified this from our institutional experience. This serves as a potential area of further research which should include a comparative analysis of costeffectiveness between these modalities.

\section{CONCLUSION}

Modern head and neck vascularized composite free-tissue reconstruction offers numerous techniques to achieve optimal functional and aesthetic outcomes after oncologic ablation, complex maxillofacial trauma or deformity. Advanced technologies incorporating patient-specific anatomic detail have expanded the boundaries of head and neck reconstruction with ever-improving precision. In this review, we familiarize the surgeons with the available techniques for bony free flap contouring and offer insight and recommendations as to their best applications.

\section{DECLARATIONS}

\section{Authors' contributions}

The primary literature review and article collection along with manuscript preparation and editing: Kain JJ The manuscript preparation and editing: Birkeland AC

The manuscript preparation and editing as well as supplied case examples: Bewley AF 


\section{Availability of data and materials}

Not applicable.

\section{Financial support and sponsorship}

None.

\section{Conflicts of interest}

All authors declared that there are no conflicts of interest.

\section{Ethical approval and consent to participate}

Not applicable.

\section{Consent for publication}

Not applicable.

\section{Copyright}

(C) The Author(s) 2021.

\section{REFERENCES}

1. Hernigou P. History of external fixation for treatment of fractures. Int Orthop 2017;41:845-53. DOI PubMed

2. Roberts WR. Control of mandibular fragments by external fixation. Br Dent J 1946;80:257. PubMed

3. Kazi AA, Lee TS, Vincent A, Sokoya M, Sheen D, Ducic Y. The role of external fixation in trauma and reconstruction of the mandible in the age of rigid fixation. Facial Plast Surg 2019;35:614-22. DOI PubMed

4. Marmulla R, Niederdellmann H. Surgical planning of computer-assisted repositioning osteotomies. Plast Reconstr Surg ;1999:104:938-44. DOI PubMed

5. Culie D, Dassonville O, Poissonnet G, Riss JC, Fernandez J, Bozec A. Virtual planning and guided surgery in fibular free-flap mandibular reconstruction: a 29-case series. Eur Ann Otorhinolaryngol Head Neck Dis 2016;133:175-8. DOI PubMed

6. Azuma M, Yanagawa T, Ishibashi-Kanno N, et al. Mandibular reconstruction using plates prebent to fit rapid prototyping 3dimensional printing models ameliorates contour deformity. Head Face Med 2014;10:45. DOI PubMed PMC

7. Yan R, Luo D, Qin X, Li R, Rong Q, Hu M. Digital modeling for the individual mandibular 3D mesh scaffold based on 3D printing technology. Zhonghua Kou Qiang Yi Xue Za Zhi 2016;51:280-5. DOI PubMed

8. Shehab M, Hamid NMA, Askar NA, Elmardenly AM. Immediate mandibular reconstruction via patient-specific titanium mesh tray using electron beam melting/CAD/rapid prototyping techniques: One-year follow-up. Int J Med Robot 2018;14:e1895. DOI PubMed

9. Bergman SA, Elias EG, Didolkar MS, Morris DM. Maintenance of function and esthetics after partial mandibulectomy without bone grafting. J Oral Surg 1981;39:421-5. PubMed

10. Louis PJ, Fernandes R. Temporary stabilization of the mandible with an external fixation device. J Oral Maxillofac Surg 2001;59:1374-5. DOI PubMed

11. Urken ML, Weinberg H, Vickery C, Buchbinder D, Lawson W, Biller HF. Oromandibular reconstruction using microvascular composite free flaps. Report of 71 cases and a new classification scheme for bony, soft-tissue, and neurologic defects. Arch Otolaryngol Head Neck Surg 1991;117:733-44. DOI PubMed

12. Foster RD, Anthony JP, Sharma A, Pogrel MA. Vascularized bone flaps versus nonvascularized bone grafts for mandibular reconstruction: An outcome analysis of primary bony union and endosseous implant success. Head Neck 1999;21:66-71. DOI PubMed

13. Cordeiro PG, Disa JJ, Hidalgo DA, Hu QY. Reconstruction of the mandible with osseous free flaps: a 10-year experience with 150 consecutive patients. Plast Reconstr Surg 1999;104:1314-20. DOI PubMed

14. Ung F, Rocco JW, Deschler DG. Temporary intraoperative external fixation in mandibular reconstruction. Laryngoscope 2002;112:1569-73. DOI PubMed

15. Cornelius CP, Augustin JB, Sailer LK. External pin fixation for stabilization of the mandible--comeback of a method: historical review and first experiences with the 'mandible external fixator'. Oral Maxillofac Surg 2009;13:1-14. DOI PubMed

16. Witjes MJH, Schepers RH, Kraeima J. Impact of 3D virtual planning on reconstruction of mandibular and maxillary surgical defects in head and neck oncology. Curr Opin Otolaryngol Head Neck Surg 2018;26:108-14. DOI PubMed

17. Vural E, Yuen JC. Combining use of resin models with external fixation in mandibular reconstruction. Arch Otolaryngol Head Neck Surg 2007;133:603-7. DOI PubMed

18. Schouman T, Bertolus C, Chaine C, Ceccaldi J, Goudot P. Surgery guided by customized devices: reconstruction with a free fibula flap. Rev Stomatol Chir Maxillofac Chir Orale 2014;115:28-36. DOI PubMed

19. Hanasono MM, Skoracki RJ. Computer-assisted design and rapid prototype modeling in microvascular mandible reconstruction. Laryngoscope 2013;123:597-604. DOI PubMed 
20. Seruya M, Fisher M, Rodriguez ED. Computer-assisted versus conventional free fibula flap technique for craniofacial reconstruction: an outcomes comparison. Plast Reconstr Surg 2013;132:1219-28. DOI PubMed

21. Chang EI, Jenkins MP, Patel SA, Topham NS. Long-term operative outcomes of preoperative computed tomography-guided virtual surgical planning for osteocutaneous free flap mandible reconstruction. Plast Reconstr Surg 2016;137:619-23. DOI PubMed

22. Zhang L, Liu Z, Li B, Yu H, Shen SG, Wang X. Evaluation of computer-assisted mandibular reconstruction with vascularized fibular flap compared to conventional surgery. Oral Surg Oral Med Oral Pathol Oral Radiol 2016;121:139-48. DOI PubMed

23. Fatima A, Hackman TG, Wood JS. Cost-effectiveness analysis of virtual surgical planning in mandibular reconstruction. Plast Reconstr Surg 2019;143:1185-94. DOI PubMed

24. Zweifel DF, Simon C, Hoarau R, Pasche P, Broome M. Are virtual planning and guided surgery for head and neck reconstruction economically viable? J Oral Maxillofac Surg 2015;73:170-5. DOI PubMed

25. Toto JM, Chang EI, Agag R, Devarajan K, Patel SA, Topham NS. Improved operative efficiency of free fibula flap mandible reconstruction with patient-specific, computer-guided preoperative planning. Head Neck 2015;37:1660-4. DOI PubMed

26. Mazzola F, Smithers F, Cheng K, et al. Time and cost-analysis of virtual surgical planning for head and neck reconstruction: A matched pair analysis. Oral Oncol 2020;100:104491. DOI PubMed

27. Saad A, Winters R, Wise MW, Dupin CL, St Hilaire H. Virtual surgical planning in complex composite maxillofacial reconstruction. Plast Reconstr Surg 2013;132:626-33. DOI PubMed

28. Largo RD, Garvey PB. Updates in head and neck reconstruction. Plast Reconstr Surg 2018;141:271e-85e. DOI PubMed

29. Matros E, Santamaria E, Cordeiro PG. Standardized templates for shaping the fibula free flap in mandible reconstruction. $J$ Reconstr Microsurg 2013;29:619-22. DOI PubMed

30. Kaye R, Goldstein T, Zeltsman D, Grande DA, Smith LP. Three dimensional printing: A review on the utility within medicine and otolaryngology. Int J Pediatr Otorhinolaryngol 2016;89:145-8. DOI PubMed

31. D'urso PS, Barker TM, Earwaker WJ, et al. Stereolithographic biomodelling in cranio-maxillofacial surgery: a prospective trial. $J$ Craniomaxillofac Surg 1999;27:30-7. DOI PubMed

32. Velasco I, Vahdani S, Ramos H. Low-cost method for obtaining medical rapid prototyping using desktop 3D printing: a novel technique for mandibular reconstruction planning. J Clin Exp Dent 2017;9:e1103-8. DOI PubMed PMC

33. Hong CJ, Giannopoulos AA, Hong BY, et al. Clinical applications of three-dimensional printing in otolaryngology-head and neck surgery: A systematic review. Laryngoscope 2019;129:2045-52. DOI PubMed

34. Chan HH, Siewerdsen JH, Vescan A, Daly MJ, Prisman E, Irish JC. 3D rapid prototyping for otolaryngology-head and neck surgery: applications in image-guidance, surgical simulation and patient-specific modeling. PLoS One 2015;10:e0136370. DOI PubMed PMC

35. Suzuki M, Ogawa Y, Kawano A, Hagiwara A, Yamaguchi H, Ono H. Rapid prototyping of temporal bone for surgical training and medical education. Acta Otolaryngol 2004;124:400-2. DOI PubMed 